\title{
Tailor-made $\mathrm{pH}$-responsive poly (Choline Phosphate) prodrug as a drug delivery system for rapid cellular internalization
}

Wenliang Wang, ${ }^{\dagger+}$ Bo Wang, ${ }^{\dagger}$ Xiaojing Ma, ${ }^{* \dagger}$ Sanrong Liu, ${ }^{\dagger}$ Xudong Shang ${ }^{\dagger}$ and Xifei Yu ${ }^{* \dagger+}$

${ }^{\dagger}$ The Polymer Composites Engineering Laboratory, Changchun Institute of Applied Chemistry, Chinese Academy of Sciences, Changchun 130022, P.R. China. E-mail: xjma@ciac.ac.cn, xfyu@ciac.ac.cn; Tel: +8643185262678.

tUniversity of Chinese Academy of Sciences, Beijing 100049, P.R. China.

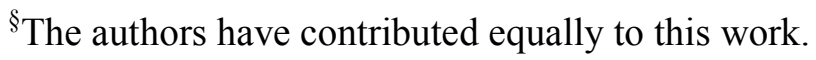




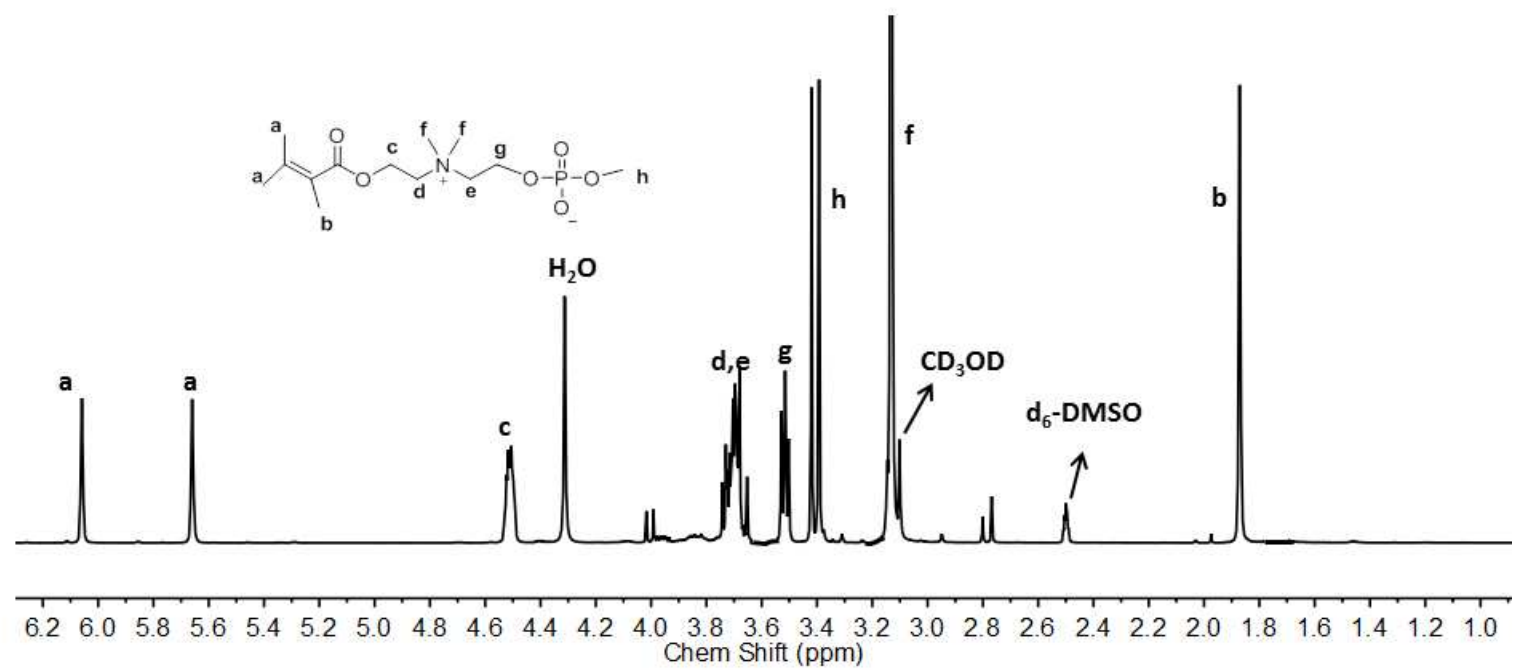

Fig S1. ${ }^{1} \mathrm{H}$ NMR spectra of MCP in $\mathrm{d}_{6}$-DMSO and $\mathrm{CD}_{3} \mathrm{OD}$. 


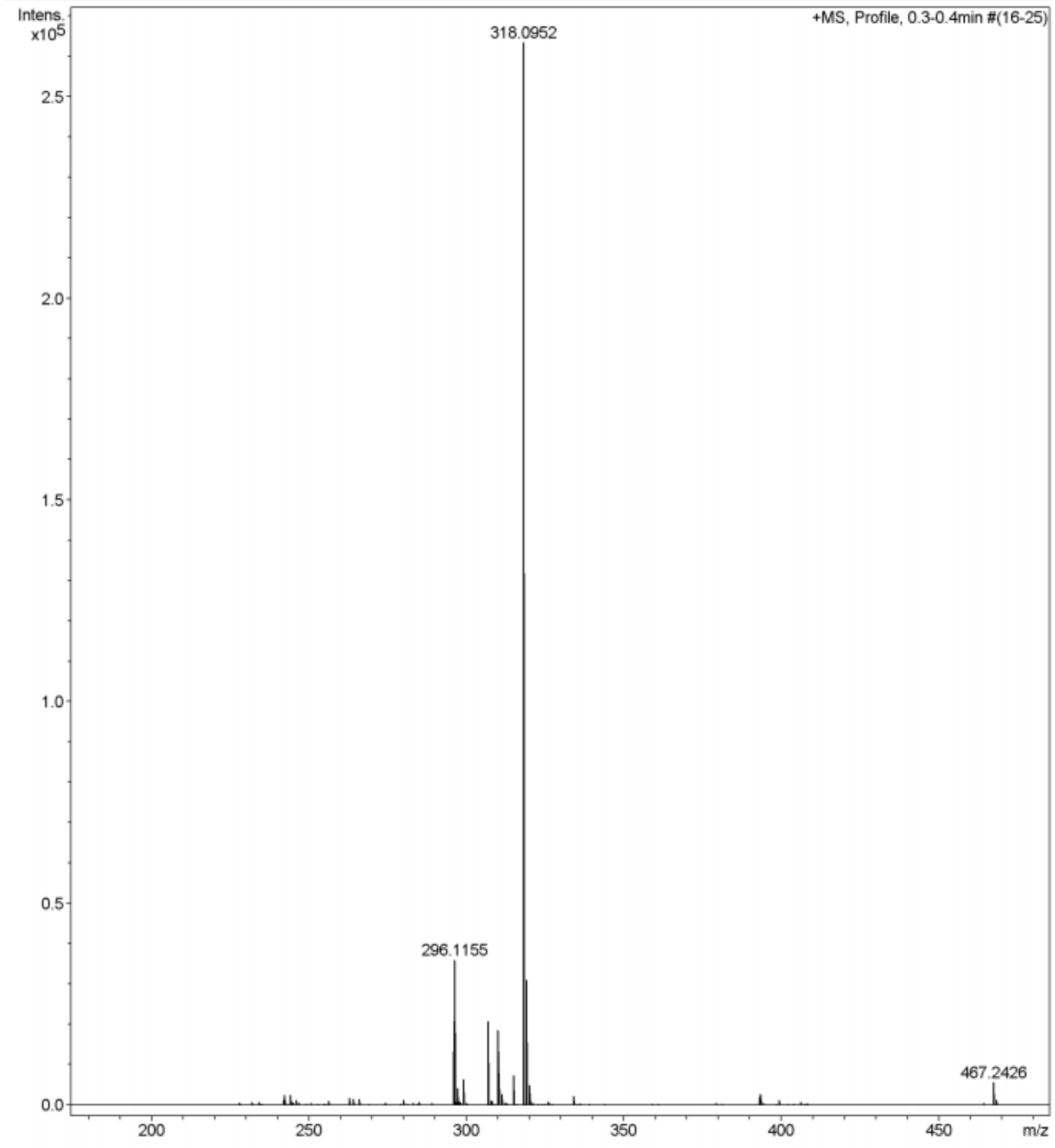

Fig S2. The MS image of MCP monomer. 


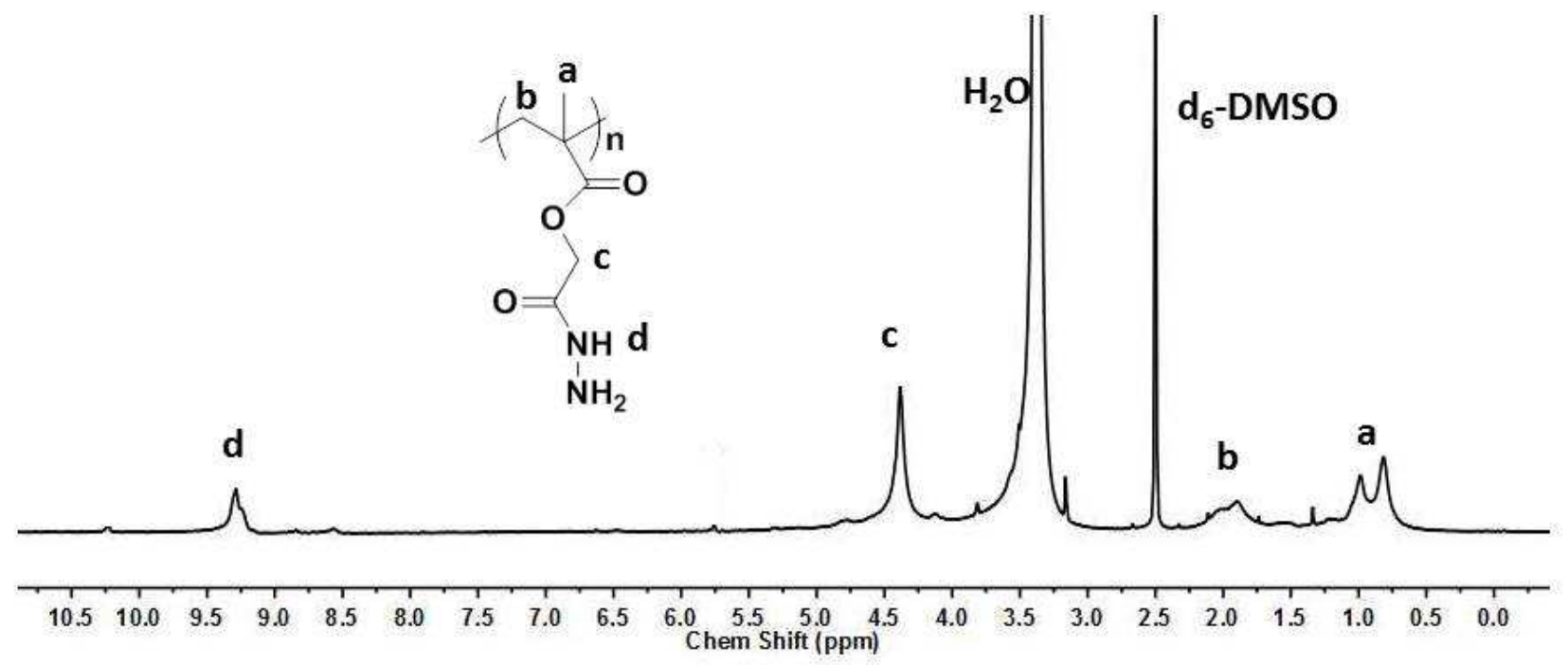

Fig S3. ${ }^{1} \mathrm{H}$ NMR spectrum of PMEMA-Hydrazide in d6-DMSO.

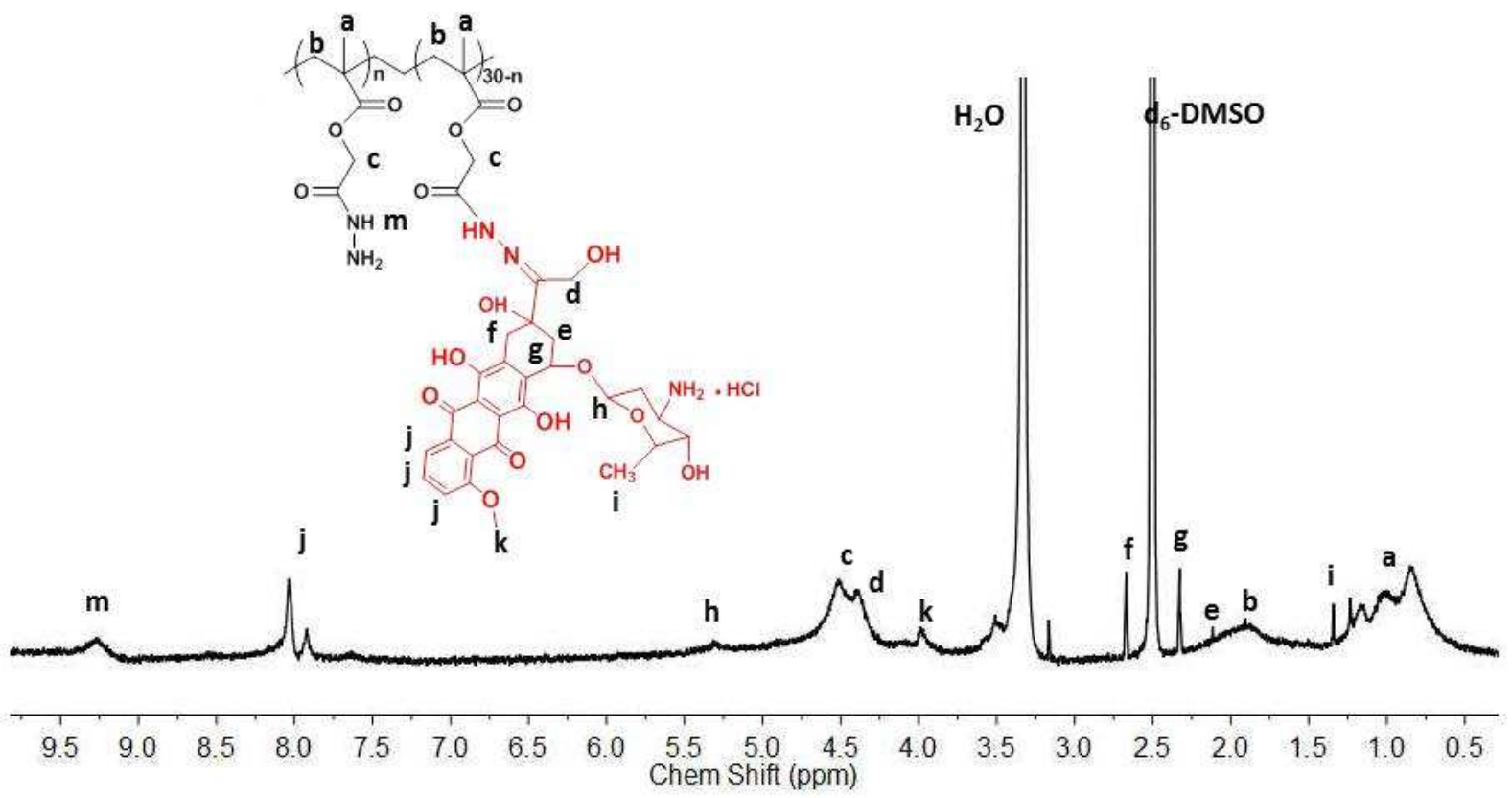

Fig S4. ${ }^{1} \mathrm{H}$ NMR spectrum of PMEMA-Hyd-Dox in $\mathrm{d}_{6}$-DMSO. 


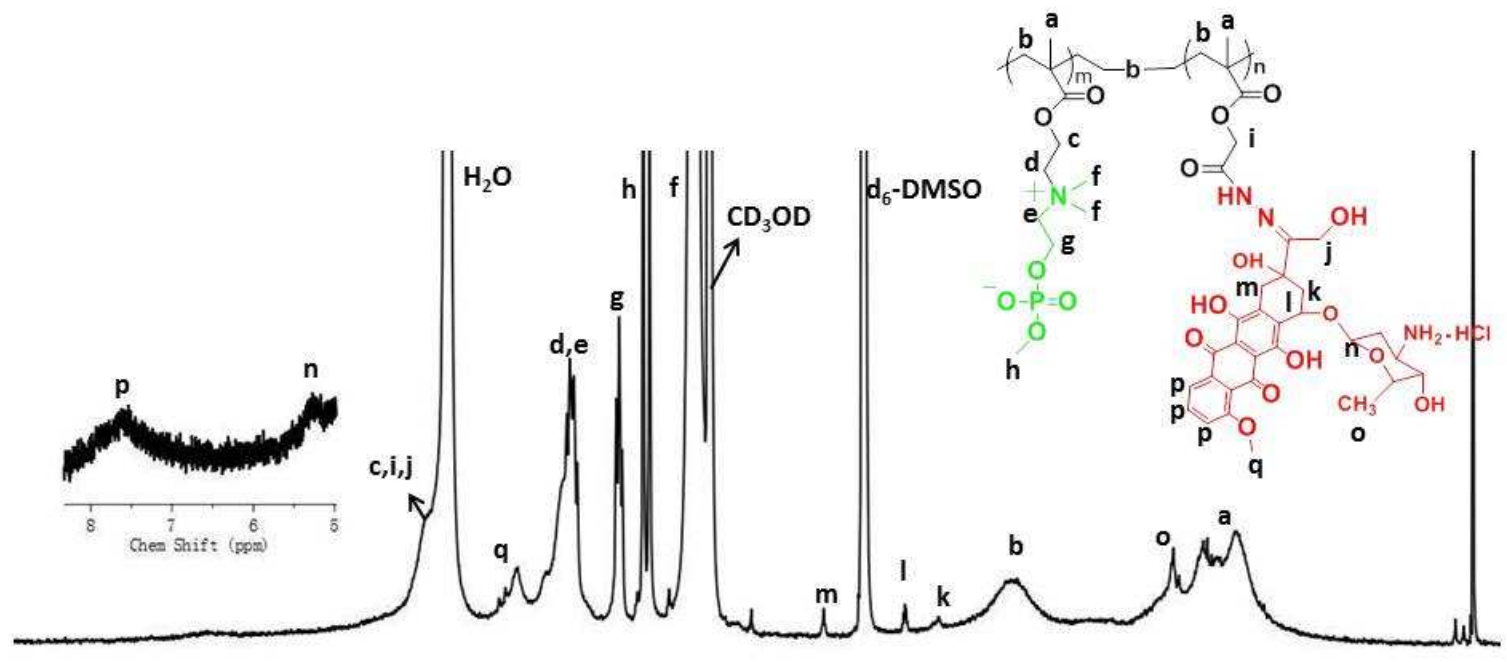

\begin{tabular}{llllllllllllllllllllllllllllllllllllllllllll}
\hline 6.0 & 5.8 & 5.6 & 5.4 & 5.2 & 5.0 & 4.8 & 4.6 & 4.4 & 4.2 & 4.0 & 3.8 & 3.6 & 3.4 & 3.2 & 3.0 & 2.8 & 2.6 & 2.4 & 2.2 & 2.0 & 1.8 & 1.6 & 1.4 & 1.2 & 1.0 & 0.8 & 0.6 & 0.4 & 0.2 & 0.0
\end{tabular}

Fig S5. ${ }^{1} \mathrm{H}$ NMR spectrum of PCP-Dox in $\mathrm{d}_{6}$-DMSO and $\mathrm{CD}_{3} \mathrm{OD}$.

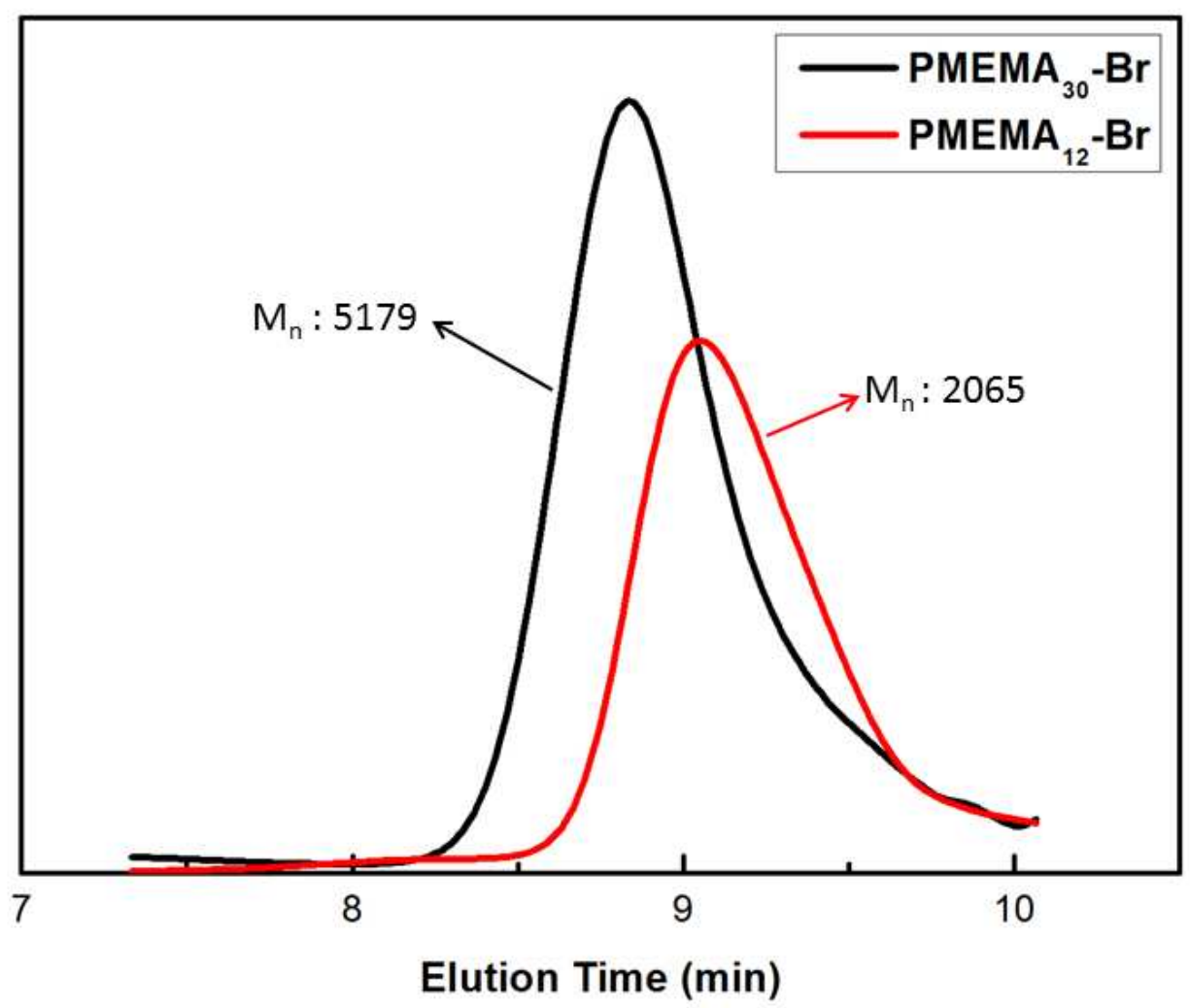

Figure S6. The GPC date of PMEMA (elution: THF, PS standards) 


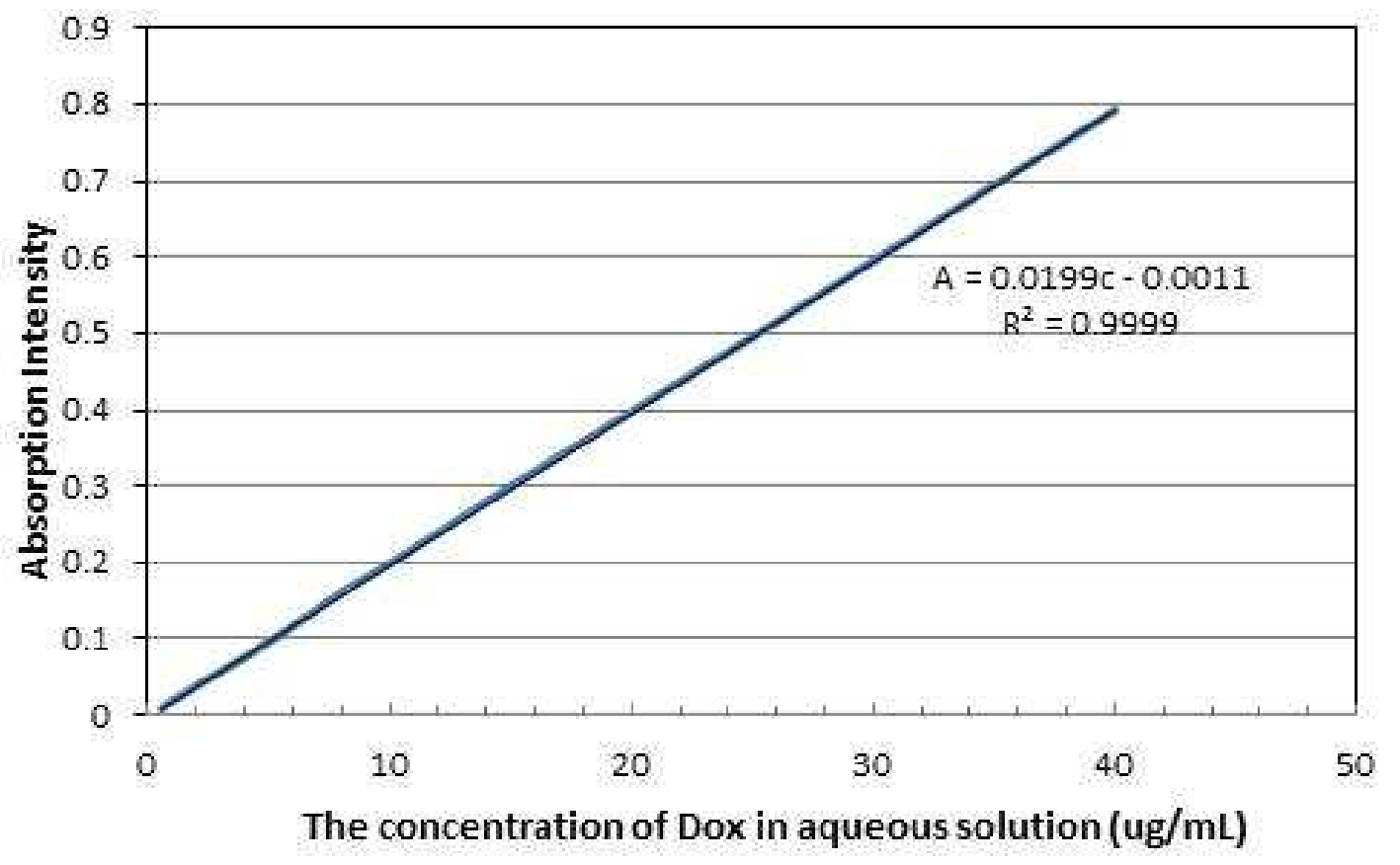

Fig S7. The the calibration curve of Dox in aqueous solution 

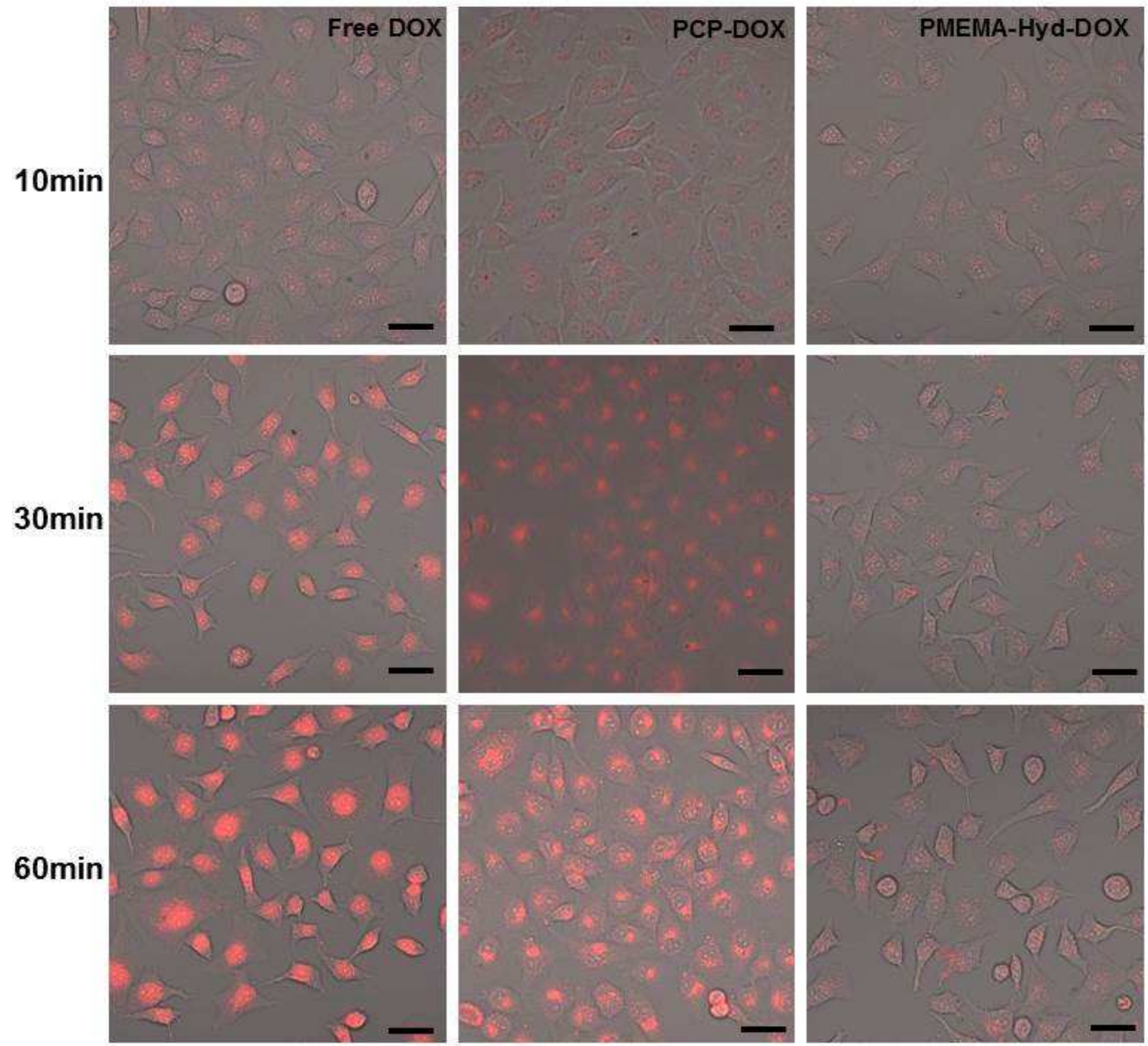

Figure S8. Confocal microscopy images of MCF-7 treated by free Dox, prodrug and PMEMA -Dox (with equivalent Dox concentration $10 \mu \mathrm{g} / \mathrm{mL}$ ) respectively for 10,30 and $60 \mathrm{~min}$. Scale bar: $50 \mu \mathrm{m}$. 


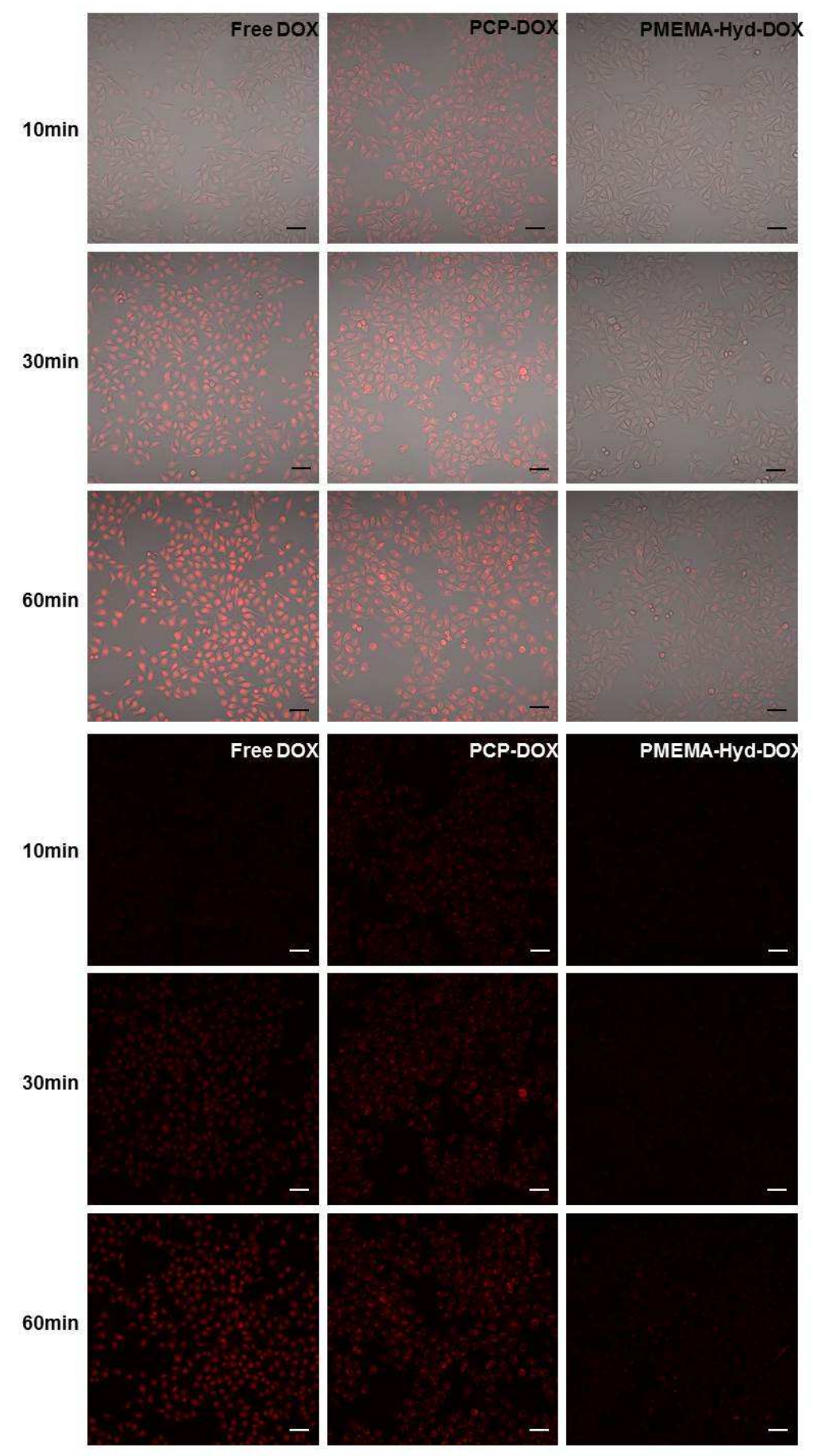

Figure S9. Confocal microscopy images of A549 treated by free Dox, prodrug and

PMEMA-Hyd-Dox (with equivalent Dox concentration $10 \mu \mathrm{g} / \mathrm{mL}$ ) respectively for 10, 30 and $60 \mathrm{~min}$. Scale bar: $50 \mu \mathrm{m}$. 


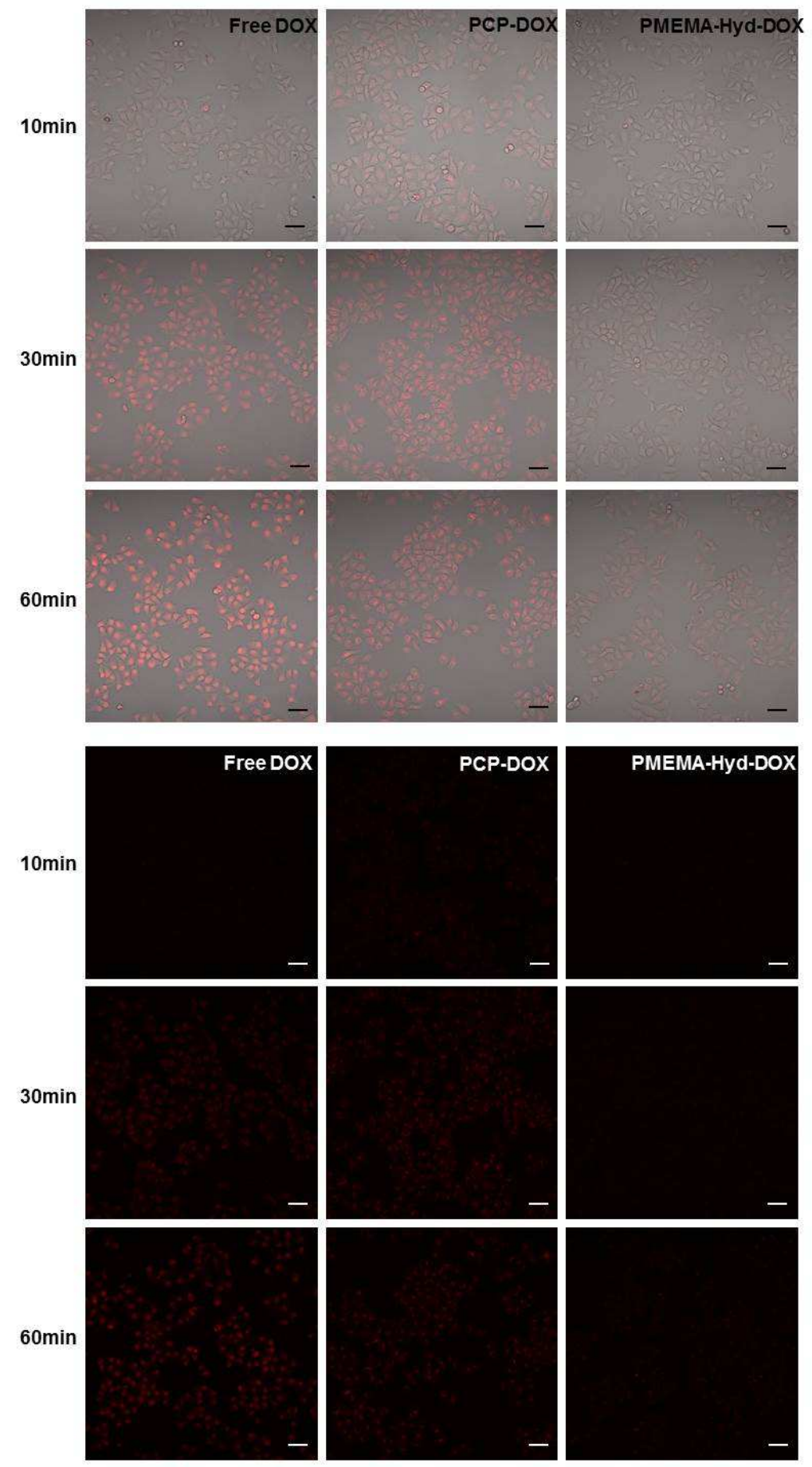

Figure S10. Confocal microscopy images of HepG2 cells treated by free Dox, prodrug and PMEMA-Hyd-Dox (with equivalent Dox concentration $10 \mu \mathrm{g} / \mathrm{mL}$ ) respectively for 10,30 and $60 \mathrm{~min}$. Scale bar: $50 \mu \mathrm{m}$. 

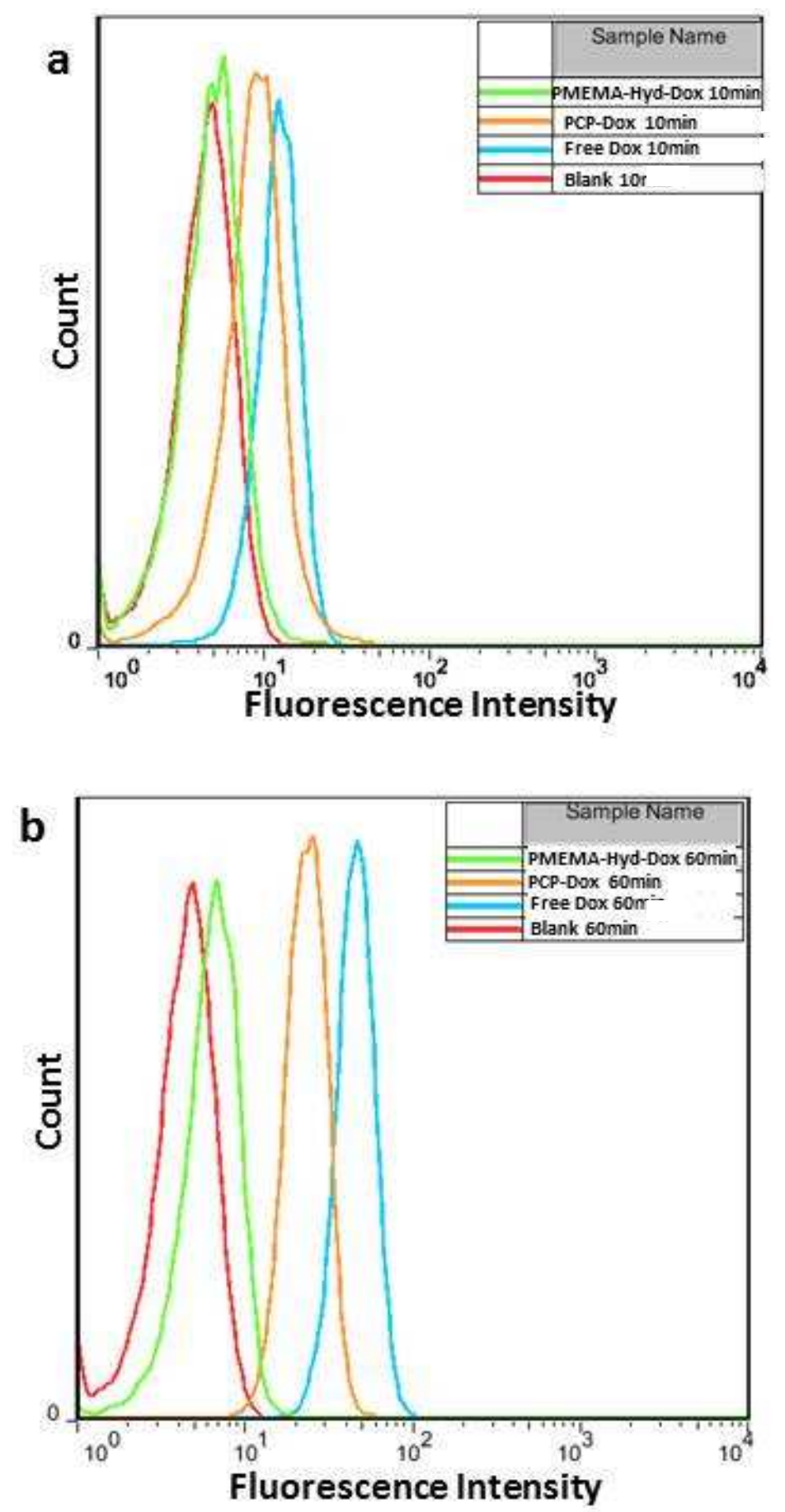

Figure S11. Flow cytometry analysis of A549 cells treated by free Dox, PCP-Dox prodrug and control with equivalent Dox concentration to be $10 \mu \mathrm{g} / \mathrm{mL}$, respectively for $10 \mathrm{~min}(\mathrm{a})$, and $60 \mathrm{~min}(\mathrm{~b})$. 

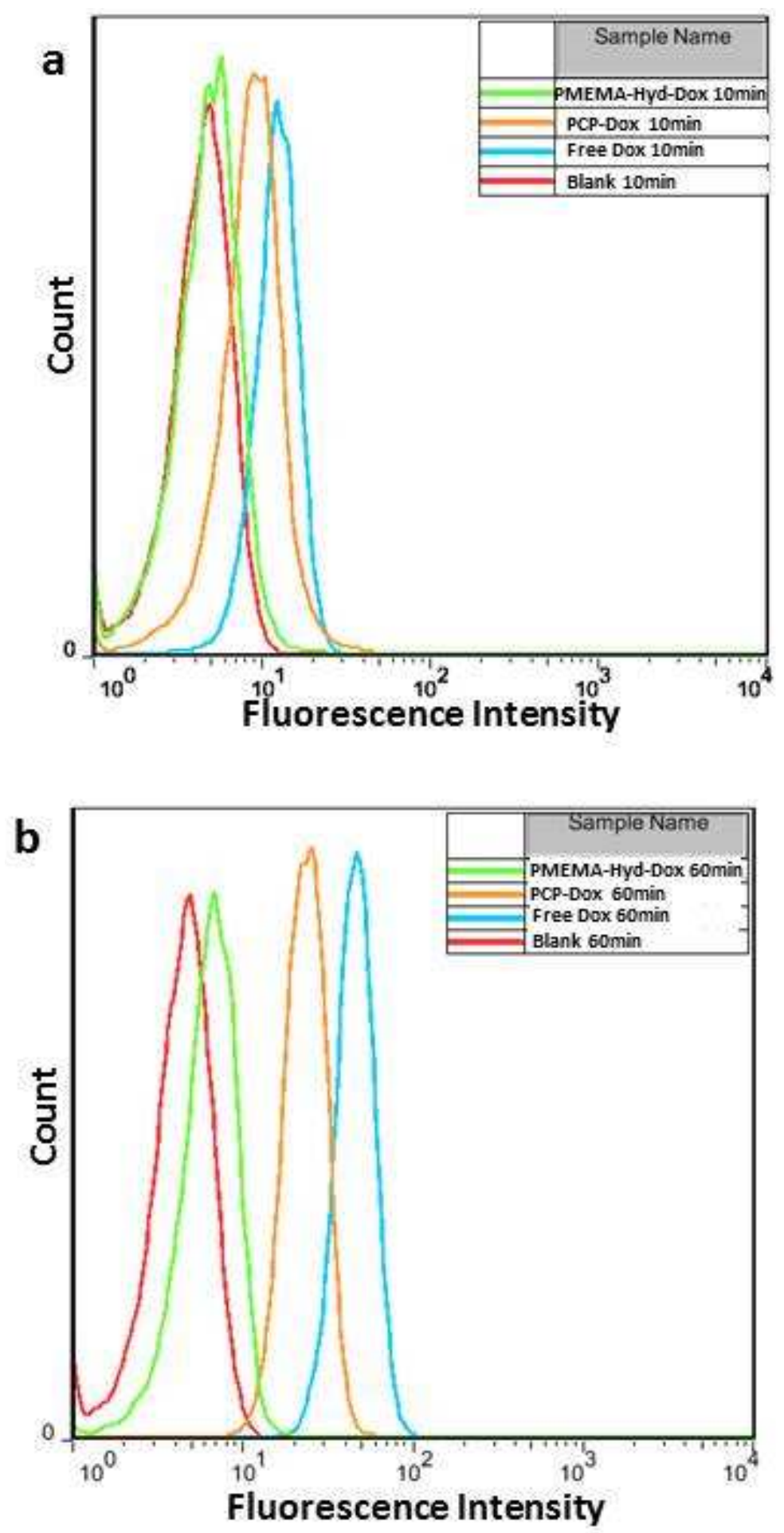

Figure S12. Flow cytometry analysis of HePG-2 cells treated by free Dox, PCP-Dox prodrug and control with equivalent Dox concentration to be $10 \mu \mathrm{g} / \mathrm{mL}$, respectively for $10 \mathrm{~min}(\mathrm{a})$, and $60 \mathrm{~min}(\mathrm{~b})$. 

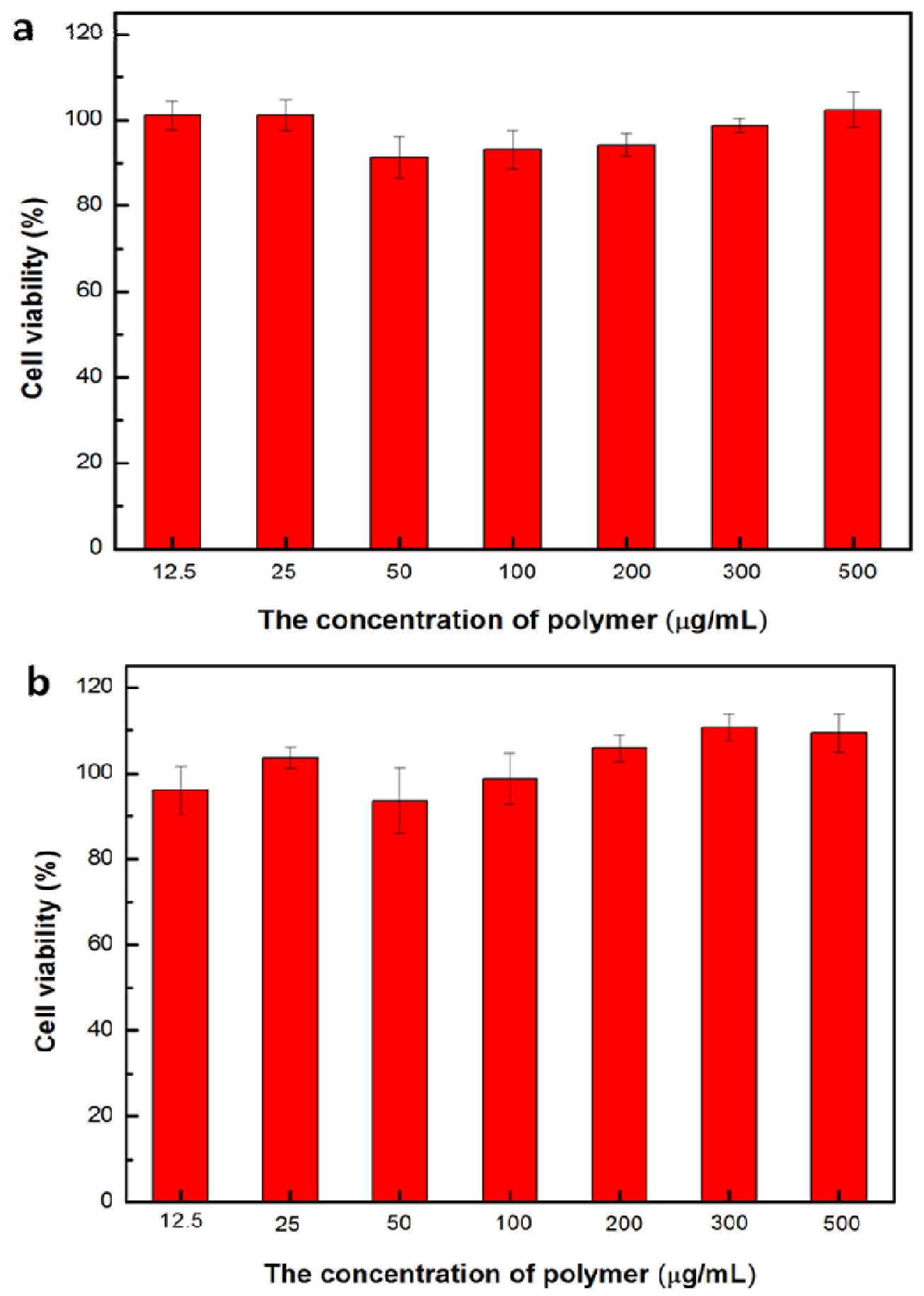

Figure S13. (a) Cell viability of A549, (b) and HepG2 cells incubated with various concentrations of the polymer precursor for $48 \mathrm{~h}$. 

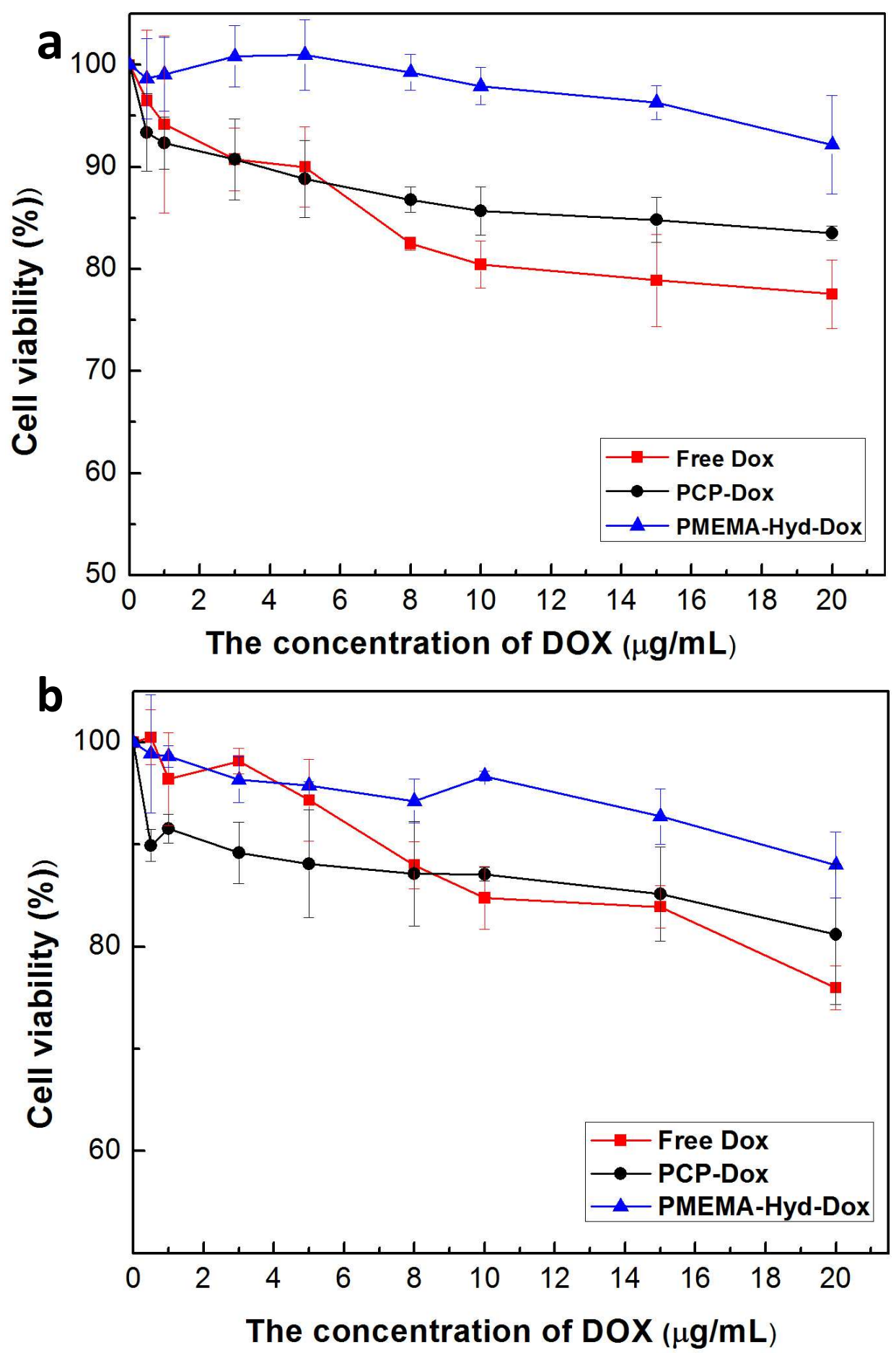

Figure S14. (a) Cell viability of A549, (b) and HepG2 cells incubated with different concentrations of free DOX, PCP-Dox prodrug and control for $1 \mathrm{~h}$, then replaced with fresh serum-free DMEM and incubated for another $47 \mathrm{~h}$. 